\title{
MUCOSAL FLAP VERSUS MUCOPERIOSTEAL FLAP IN RIDGE SPLITTING AND SIMULTANEOUS IMPLANT PLACEMENT USING PIEZOSURGERY (A RANDOMIZED CONTROLLED CLINICAL TRIAL)
}

\author{
Ziad T. Mahmoud ${ }^{I} M S$, Mostafa M. El-Dibany ${ }^{2} P h D$, Sherif M. El-Ghamrawy ${ }^{2} P h D$, \\ Saeeda M. Osman ${ }^{2} P h D$, Angelo C. Troedhan ${ }^{3} P h D$
}

\begin{abstract}
INTRODUCTION: Ridge split procedures are commonly performed for horizontal widening-augmentation of narrow ridges which would otherwise preclude implant placement. Post-surgical vertical and horizontal crestal bone loss that might occur secondary to ridge splitting techniques present a serious obstacle to the success of implant placement and prognosis.

OBJECTIVES: The evaluation of the effectiveness of maintaining the periosteal attachment of the buccal and lingual cortical plates to reduce and/or prevent crestal bone loss that might occur at the crestal margin of dental implants placed immediately in posterior mandibular alveolar ridges splitted using piezosurgery.

MATERIALS AND METHODS: That was a randomized controlled clinical trial. The study population included 16 patients with edentulous posterior mandibular alveolar ridges. The sample was selected conveniently to fulfill a list of inclusion and exclusion criteria. Then the selected participants were allocated randomly into two equal groups each including 8 patients. A full thickness mucoperiosteal flap were performed in the control group patients, while a split thickness mucosal flap was done in the study group patients. All patients had undergone a mandibular ridge splitting technique using piezoelectrical surgical device. After ridge-splitting-porcedure implants with interpositional grafts were placed immediately. Assessments included measurements of the linear changes in the marginal bone surrounding the implants immediately postoperative as baseline, 3,6 and 9 months postoperative.

RESULTS: The statistical analysis of measurements obtained from both groups showed no significant difference between control and study groups regarding pain and edema assessment, while probing depth, and marginal bone level showed significant difference between both groups in favor to the study group.

CONCLUSIONS: The ridge splitting technique using a partial thickness flap could be a successful option for the reduction of marginal bone loss around immediately inserted implants.

KEY WORDS: Ridge splitting, Piezosurgery, split thickness flap, Full thickness flap, horizontal distraction, posterior edentulous mandible.

1- Assistant Lecturer of Oral and Maxillofacial surgery, Faculty of Dentistry, Alexandria University.

2- Professor of Oral and Maxillofacial surgery, Faculty of Dentistry, Alexandria University.

3- Visiting Professor of Oral and Maxillofacial surgery, Faculty of Dentistry, Alexandria University \& University of Health Science Vientiane.
\end{abstract}

\section{INTRODUCTION}

Several surgical procedures have been used successfully for augmentation of the horizontal-wise deficient alveolar ridge, such as guided bone regeneration, cortical autogenous onlay block grafting, ridge expansion, and distraction osteogenesis. These methods have drawbacks, such as greater financial cost, an increase in the overall treatment period, and possible donor site morbidity (1-4).

Ridge split augmentation aims to the creation of a new implant bed by longitudinal osteotomy of the alveolar ridge. To start, adequate bone height for implant placement should be present because the splitting of the crest will not increase bone volume vertically. A minimum of $3 \mathrm{~mm}$ of bone width, including at least $1 \mathrm{~mm}$ of cancellous bone, is desired to insert a chisel between cortical plates and consequently expand the cortical bone (3).

Piezoelectric surgery is a predictable method that can be used to perform split-crest procedures without the risk of bone thermo-necrosis and it carries a reduced risk of damage of the adjacent soft tissues. Because non-serrated tips are available, the procedure is very safe when using the piezoelectric device, even if the inferior alveolar nerve is accidentally touched Bone cutting efficiency is satisfactory with the current devices because of the enhanced oscillation power. Ultrasonic devices have the ability to cut mineralized hard tissues as teeth or bone in a very safe and precise way, with minor tissue damage $(5,6)$.

However, crestal bone loss that might occur secondary to ridge splitting techniques in the healing-period presents a serious obstacle to the long-term success of implant placement and has become a critical and challenging feature of the described procedure. In this study we adhered to the technique described by Chiapasco et al (7) who recommended to raise split thickness mucosal flap and not to strip off the periosteum from the labial plate in order to avoid interruption of the blood supply and to allow rapid revascularization of the expanded plate of bone and the split-gap. The periosteum provides another function in treating possible iatrogenic fractures that might occur during the splitting procedure by preventing any cracked segment from dislocation and maintaining the blood supply.

The hypothesis for this study was based on the assumption that marginal bone loss around implants will be reduced in the study group (split thickness flaps) in comparison to the control group (full thickness flaps) due to the physiologic task of the periosteum to preserve full vitality of fractured bone and by this decreasing the amount of marginal bone level (MBL). 


\section{MATERIALS AND METHODS}

This study was carried out as a controlled clinical trial and was conducted on 16 patients, from 25-45 years old of both sexes, selected from the Out-Patient Clinic of the Oral and Maxillofacial Surgery department, Faculty of Dentistry, Alexandria University. All patients were instructed about the procedure that was performed, an informed consent was signed by each participant and an ethical clearance was obtained from the university. The sample was selected conveniently to fulfill the following inclusion and exclusion criteria.

The selected 16 participants then were allocated randomly in two equal groups each consisting of 8 patients. Group 1:(control group) 8 patients had been treated after raising a full-thickness mucoperiostal flap prior to ridgesplitting of the narrow alveolar crest in the posterior mandible with simultaneous implant placement. Group 2: (study group) 8 patients had been treated after raising a split-mucosal flap prior to ridge-splitting of the narrow alveolar crest in the posterior mandible with simultaneous implant placement.

Criteria of Patient Selection included a partially edentulous posterior mandibular alveolar ridge having the following criteria: A posterior mandibular vertical dimension of at least $10 \mathrm{~mm}$ measured from the alveolar crest to the inferior alveolar canal, Horizontal alveolar dimension ranging from 2 to $4 \mathrm{~mm}$ at the top of the crest and 6 to $8 \mathrm{~mm}$ at the basal part of the ridge roofing the mandibular nerve canal, measured from the outer surface of the buccal to the outer surface of the lingual cortex. Patients were excluded as study subjects if they fall into the following criteria: Any systemic disease directly affecting bone metabolism and healing, local disease that may interfere with bone healing, a history of any grafting procedure at the designated edentulous ridge.

Implant type: Tapered screw implants with surface (Aluminium oxide blasted and etched) available in different lengths and diameters -Q2 Implant (Trinon Titanuim, Germany)

Bone Graft material: Allograft osteoconductive gap filler composed of Biphasic calcium phosphate $(60 \%$ HA / $40 \%$ beta-TCP) and Biolinker with Long-term volume preservation (Easygraft ${ }^{\mathrm{TM}}$, Guidor Biodegredable, Sunstar, Swizerland).

\section{Preoperative Phase:}

Preoperative Preparation done both clinically and radiographically; Clinical Examination included a basic panoramic X-ray and thorough medical and dental history, followed by Clinical bucco-lingual measurements done using a caliper to ensure the patients would meet our initial inclusion criteria prior to further investigations. Then Impressions were taken and a diagnostic wax-up were performed on the study cast to fabricate a prosthetically driven vacuum-formed stent in order to locate the proposed osteotomy sites during surgery. Radiographic evaluation done using cone beam computed tomography (CBCT) scan as a final investigation for the assessment of the buccolingual width and vertical height above the mandibular canal of the edentulous alveolar ridge. Then the width of each implant site was measured accurately on the reformatted cross-sectional images at 4 points in the vertical plane (at top of the crest, at $3 \mathrm{~mm}$, at $6 \mathrm{~mm}$, and at $9 \mathrm{~mm}$ towards the mandibular canal).

\section{Operative Phase:}

Surgical procedures were undergone under local anaesthesia using articaine hydrochloride 4\% and levonordefrin (Septanest; Septodont, France). Inferior Alveolar Nerve block were given to all patients along with buccal nerve infiltration of the entire surgical site, and povidone-iodine surgical scrub (Mundipharma, UK) applied to the patient.

\section{Group 1 (control group)- Full Thickness Mucoperiosteal} Flap

A three-line pyramidal mucoperiosteal flap was raised in which the crestal incision was carried out slight lingually in order to compensate for the increase in ridge width following the ridge splitting with the buccal releaseincisions minimum $2 \mathrm{~mm}$ mesial and distal of the projected buccal relief-osteotomies to prevent later dehiscence in this critical area. Oblique releasing incisions were made $2 \mathrm{~mm}$ away from the papillae of the teeth enclosing the edentulous area (papilla preservation incision). Reflection of the buccal and lingual mucoperiosteal flap was done.

The longitudinal mesiodistal midcrestal osteotomy was performed using piezosurgery (Acteon, Satelec, France) down to a depth between a minimum of $6 \mathrm{~mm}$ and a maximum of $8 \mathrm{~mm}$ depending on the measured alveolar crest-height above the mandibular canal and 2-3 mm shorter in depth than the full length of the planned implant with accuracy of $+/-0,5 \mathrm{~mm}$ using the CS1 and CS2 tips. To avoid unintended iatrogeneic fractures in the horizontal distraction-process, the CS3 scalpel was then used for the buccal relief-osteotomies at the mesial and distal end of the longitudinal osteotomy with corresponding identical vertical depths.

The conical CS4, CS5 and CS6 tips from the CrestSplitting Kit were then used gradually to increase the resulting osteotomy-gap from 1 to $4 \mathrm{~mm}$. Implant-insertion started immediately after the horizontal expansion, following precisely the drill-protocol provided by the implant-manufacturer and followed by implant insertion using a torque-wrench. Synthetic bone graft material packed into the interpositional spaces to prevent soft tissue invasion to the surgical site. Finally, a periosteal releasing incision were performed on the base of the inner aspect of the flap (periosteal side) in order to obtain tension free woundclosure and to compensate for increased ridge width. Closure was performed using 5-0 Vicryl sutures (Ethicon, UK). (Figures 1\& 2)
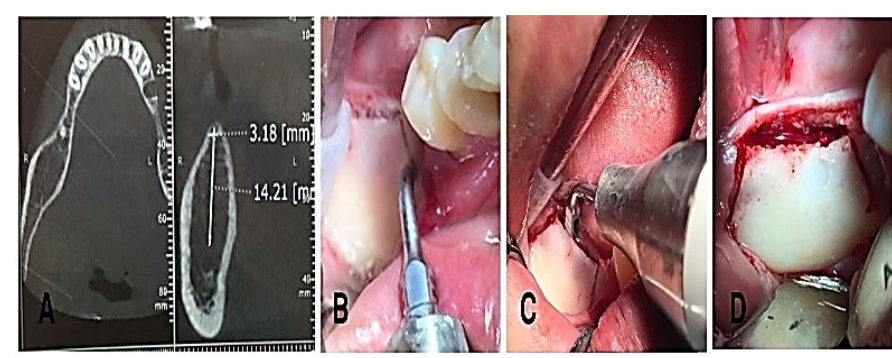

Figure 1: Control Group

A: Preoperative $\mathrm{CBCT}$ showing ridge width less than $3 \mathrm{~mm}$ at the crest.

B: Full thickness mucoperiosteal flap reflected and CS3 tip for vertical relief buccal osteotomies.

C: Piezoelectric horizontal distraction of the ridge using CS5 tip. D: Midcrestal gap created 


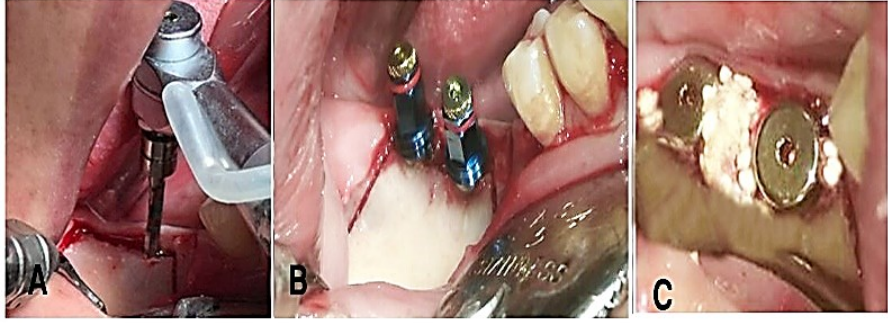

Figure 2: Control Group

A: Corresponding implant shaping drill for shaping planned implants osteotomies.

B: Implants inserted in place.

C: Easygraft crystalline granules to fill mesial and distal gaps around implants.

\section{Group 2 (study group) - Split Thickness Mucosal Flap}

A three-line pyramidal mucosal-only flap was designed with buccal mucosal-only release incisions minimum $2 \mathrm{~mm}$ mesial and distal of the projected buccal relief-osteotomies to prevent later dehiscence in this critical area, leaving the periosteum attached to the bone and raised as split thickness mucosal flap.

Sharp incisions were performed down to the bone only on top of the alveolar crest and the rest of the flap was undermined as mucosal flap beginning at the mesial buccal mucosal relief-incision with the SL 4-tip of the Piezotome and the mucosal flap reflected. A midcrestal mesiodistal osteotomy and vertical buccal relief- osteotomies were done with the same protocol as the control group using piezotome splitting tips, Implant-insertion started immediately after the horizontal expansion. Synthetic bone graft was packed into the interpositional spaces to prevent soft tissue invasion to the surgical site. Finally, tension free closure was performed using 5-0 Vicryl sutures after stretching the mucosal flap to cover the expanded ridge, synthetic bone graft and implants. (Figures $3 \& 4$ )

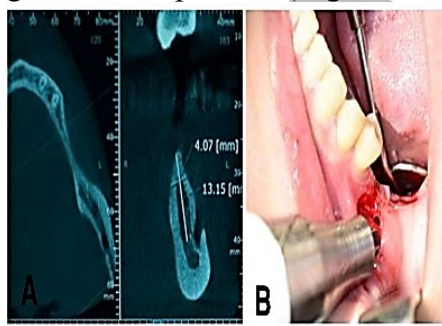

Figure 3: Study Group

A: Preoperative CBCT showing extremely narrow width of the edentulous area from the crest till the mandibular foramen.

B: Piezoelectric dissection of split thickness mucosal flap.

C: Split thickness mucosal flap reflected and CS1 for pilot midcrestal osteotomy.

D: Further piezoelectric horizontal distraction of the knife-edge ridge using CS4 tip.
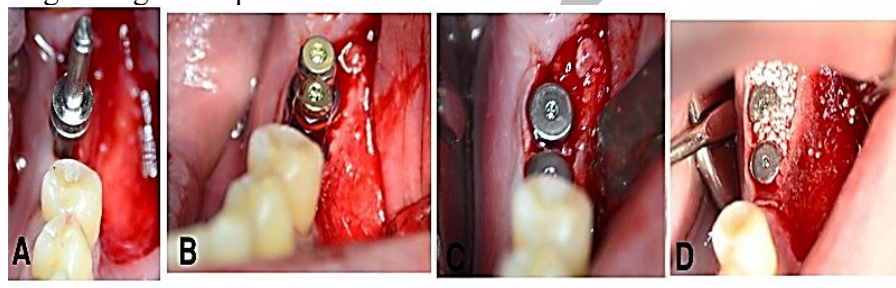

Figure 4: Study Group

A: Corresponding implant shaping drill into the midcrestal gap.

B: Implants inserted in place with their mounts.

C: Implants with their cover screws in place with obviously immediate bulging of the buccal cortex covered with periosteum. D: Easygraft crystalline granules to fill gaps around and between implants.

\section{Postoperative Phase:}

Antibiotic shielding administered post-operatively for 5 days every 12 hours (Augmentin, Glaxosmith) in addition to anti-inflammatory drugs (Brufen, Abbott). "Cool-Packs" over the cheek and lower lip were applied for 20 min every hour for 6 hours postoperatively. Patients were kept on a clear fluid diet for the first 24 hours, then a mushy-food diet has to be maintained for the following 7 days. They were advised to use chlorhexidine oral rinse (Listerine, Johnson \& Johnson) three times daily for 1 week. Insertion of partial removable prosthesis was forbidden for 4 weeks since this might cause pressure-necrosis and affect primary bone healing.

\section{Prosthetic Phase:}

Second stage (loading) were done at 5 months postoperatively in both groups, re-opening of the implant sites were performed by punch technique in both groups. Gingival formers were inserted for 1-2 weeks to provide good gingival contour around implant collar. Impressions were taken using impression coping, then abutments were inserted. After final restorations were delivered in place, thorough check of occlusal interferences were done in both static occlusion and dynamic side shift (left-right) to exclude study-biases by crestal overload.

Postsurgical evaluation: All patients underwent clinical examination at set intervals; immediately postoperative: day 1 post-surgery, day 3 post-surgery, day 7 post-surgery, day 14 post surgery/suture-removal, 6 months and 9 months. Swelling was assessed throughout the immediate post-operative period (day 1, 3, 7, and 14) by using a caliper to measure the distance between two marked points on the skin of the face corresponding to the inferior margin of the mandible in the area of the intraoral surgical sites and comparing these measurements to the measurements obtained between the same two marks before surgery and application of anesthesia. Pain was assessed using painassessment-scale enhanced by the Wong-Baker facialgrimace-scale and number of analgesic-tablets intake at day 1, 3, 7, and 14 post-operatives. Probing depth around implants were measured during follow up at 6 and 9 months from buccal, lingual and mesiodistal aspects. Graduated periodontal probe was the tool of clinical measurement of marginal bone loss around implants.

Radiographical evaluation was performed with the same CBCT-device used preoperatively. An individually prefabricated bitewing for each patient used in all CBCTscans before and after surgery allowed for least inconsistencies and aberrations of head-positioning in the study-period. The CBCT was calibrated for each scan. CBCT assessment for the calculation of marginal bone loss (MBL): the implant was used as a reference by adjusting the cross-sectional and panoramic long axis in the center of the implant and bisecting it (showing the buccolingual and mesiodistal dimensions). On the cross-sectional view, a line was drawn just parallel to the implant, starting at the crest of the buccal plate of bone and ending at the apical level of the implant; height was recorded in half-millimeter-steps to allow for unavoidable aberrations of the CBCT-device. The same process was repeated from the lingual direction. The panoramic view (longitudinal cut) have been utilized to calculate the mesial and distal bone heights in millimeters. CBCT were done to all patients at set time intervals: before surgery, immediately postoperative, 3 months, 6 months and 9 months postoperative. 
Appropriate statistical analysis was used to evaluate the outcomes of the two groups. Means and standard deviations was calculated to describe data collected from the two groups. T-test was used to evaluate the two groups to reject or not reject the null hypothesis. The level of significance was set at $\mathrm{P}<0.05$.

\section{RESULTS}

\section{Demographic data and implants allocation}

10 female and 6 male patients aged between 25 and 45 years (mean: 35 years) had undergone Piezotome-enabled vertical alveolar crest-splitting and horizontal expansion and received a total of 22 implants. The number of inserted implants was evenly distributed in both groups (Control group: 11 implants, study-group: 11 implants).

\section{Clinical Results}

All patients experienced mild postoperative edema at day 1 and day 3 post-surgery which gradually resorbed and ceased at day 7 and day 14 post-surgery. There was no statistical significant difference between both groups regarding postoperative edema (At day $1: \mathrm{P} \geq 0.13$, at day $3: \mathrm{P} \geq 0.28$, at day 7: $\mathrm{P} \geq 0.15$, and at day 14: $\mathrm{P} \geq 0.122$ ). Painassessment-scale enhanced by the Wong-Baker facialgrimace-scale at day 1 and day 3 post-operative showed no statistically significant difference between both groups: (At day 1: $\mathrm{P} \geq 0.802$, at day $3: \mathrm{P} \geq 0.582$ ).

The probing depth of the control group (full thickness mucoperiosteal flap) revealed a mean depth of $2.20 \mathrm{~mm}$ after 6 months (min. value was $1.80 \mathrm{~mm}$, max. value was $2.50 \mathrm{~mm}$ ) and $2.73 \mathrm{~mm}$ after 9 months (min. value was $2.50 \mathrm{~mm}$, max. value was $3.0 \mathrm{~mm}$ ) whereas in the studygroup, a mean depth of $0.99 \mathrm{~mm}$ were measured after 6 months (min. value was $0.8 \mathrm{~mm}$, max. value was $1.10 \mathrm{~mm}$ ) and $1.29 \mathrm{~mm}$ after 9 months (min. value was $1.10 \mathrm{~mm}$, max. value was $1.50 \mathrm{~mm}$ ). A significant reduction in the mean probing depth of the study group was observed when compared to the control group throughout the postoperative follow up intervals at 6 and 9 months. $(\mathrm{p} \leq 0.001)$ (Table 1$)$

Table 1: Comparison between the two studied groups according to probing depth in 6 and 9 months.

\begin{tabular}{|c|c|c|c|}
\hline Probing depth & $\begin{array}{c}\begin{array}{c}\text { Control } \\
(\mathrm{n}=8)\end{array} \\
\end{array}$ & $\begin{array}{l}\text { Study } \\
(\mathrm{n}=8)\end{array}$ & ${ }^{t} p$ \\
\hline $\begin{array}{l}\text { After } 3 \text { months } \\
\text { Min. - Max. } \\
\text { Mean } \pm \text { SD. } \\
\text { Median }\end{array}$ & $\begin{array}{c}1.20-1.70 \\
1.43 \pm 0.16 \\
1.45\end{array}$ & $\begin{array}{c}0.30-0.70 \\
0.51 \pm 0.15 \\
0.50\end{array}$ & $<0.001^{*}$ \\
\hline $\begin{array}{l}\text { After } 6 \text { months } \\
\text { Min. - Max. } \\
\text { Mean } \pm \text { SD. } \\
\text { Median }\end{array}$ & $\begin{array}{c}1.80-2.50 \\
2.20 \pm 0.26 \\
2.20 \\
\end{array}$ & $\begin{array}{c}0.8-1.10 \\
0.99 \pm 0.10 \\
1.0 \\
\end{array}$ & $<0.001^{*}$ \\
\hline $\begin{array}{l}\text { After } 9 \text { Months } \\
\text { (post -loading) } \\
\text { Min. - Max. } \\
\text { Mean } \pm \text { SD. } \\
\text { Median } \\
\end{array}$ & $\begin{array}{c}2.5-3.0 \\
2.73 \pm 0.18 \\
2.75\end{array}$ & $\begin{array}{c}1.10-1.50 \\
1.29 \pm 0.14 \\
1.25 \\
\end{array}$ & $<0.001^{*}$ \\
\hline
\end{tabular}

\section{Radiographical results}

There was a significant decrease in bone height at 3,6 and 9 months postoperative when compared to the immediate postoperative height in both groups. In this study, the mean Marginal bone loss of the buccal and lingual plates in the control group was found to be $2.67 \mathrm{~mm}$ at 9 months postoperative $(17.36 \%)$, while in the study group it was found to be $1.1 \mathrm{~mm}(5.89 \%)$. The results also showed the mean mesiodistal MBL at 9 months in the control group to be $1.75 \mathrm{~mm}(12.11 \%)$, while that in the study group was $1.32 \mathrm{~mm}(9.77 \%)$. (Table 2) The percentage MBL in the study group was significantly less than that of the control group for the four surfaces. The partial thickness flap used in the study group decreased the percentage of bone loss by $8.7 \%$ for the bucco-lingual bone plates, and $2.5 \%$ for the mesiodistal bone plates.

Table 2: Comparison between the two studied groups according to buccolingual Marginal Bone Loss (MBL) in 3.6 and 9 months.

\begin{tabular}{|l|c|c|c|}
\hline $\begin{array}{c}\text { Buccolingual } \\
\text { bone loss } \\
(\mathbf{m m})\end{array}$ & $\begin{array}{c}\text { Control } \\
(\mathbf{n}=\mathbf{8})\end{array}$ & $\begin{array}{c}\text { Cases } \\
(\mathbf{n}=\mathbf{8})\end{array}$ & $\mathbf{p}$ \\
\hline $\mathbf{3}$ month & $1.0-1.73$ & $0.32-0.62$ & \\
Min. - Max. & $1.23 \pm 0.23$ & $0.44 \pm 0.11$ & $<0.001^{*}$ \\
Mean \pm SD. & 1.15 & 0.41 & \\
Median & $1.84-2.59$ & $0.73-1.14$ & \\
\hline 6 month & $2.24 \pm 0.26$ & $0.98 \pm 0.14$ & $<0.001^{*}$ \\
Min. - Max. & 2.27 & 0.98 & \\
Mean \pm SD. & & & \\
Median & $2.03-2.95$ & $0.93-1.47$ & \\
\hline 9 month & $2.67 \pm 0.35$ & $1.21 \pm 0.18$ & $<0.001^{*}$ \\
Min. - Max. & 2.80 & 1.16 & \\
Mean \pm SD. & & & \\
Median & \multicolumn{2}{|l}{} \\
\hline
\end{tabular}

\section{DISCUSSION}

Ridge splitting is a technique aimed at the creation of a new implant bed by longitudinal osteotomy of the alveolar bone where the buccal bone is repositioned laterally using a greenstick fracture. The crestal bone loss that occurs secondary to the ridge splitting technique is a serious obstacle to the success of the operation and remains the challenging feature of that procedure. Ridge splitting was first described utilizing full thickness flap reflection for greater accessibility to the alveolar ridge (8-10).

In this study we adhered to the technique described by Scipioni et al. $(11,12)$ and Chiapasco et al. (13) who recommended to raise a split thickness mucosal flap and that the periosteum should not be stripped off the labial plate in order not to affect the blood supply and to allow rapid revascularization of the expanded plate of bone. The periosteum has another function in treating the malfractures that might occur during the splitting procedure in which it prevents any cracked segment from dislodging and maintains the blood supply.

Other investigators have performed a modification of the split thickness flap reflection, making a sub-periosteal reflection at the future sites of the bony cuts (tunnelling), leaving the periosteum intact in the remainder of the bone Plate (14). Some clinicians who perform the splitting technique with delayed implant placement prefer to do a full thickness flap prior to making the corticotomies (at the first surgery) and then perform a partial thickness flap during the second surgery for implant placement in order to reduce the bone resorption $(15,16)$.

The bone cutting procedure in the present study was performed using CS1 tip (Pilot crest split tip) and CS2 tip at D2 piezotome mode to make mid-crestal cut with a vertical depth between 6-8mm according to planned implant lengths. Two vertical cuts (discharge incisions) using CS3 tip to the same length $(6-8 \mathrm{~mm})$ from the crest of the ridge down on the buccal plate both mesially and distally, in order to create a bone flap, then two vertical cuts that were done 
on the facial cortical plates to aid the mobilization of the labial cortex in a lateral direction and to confine the cutting procedure to the split region. It is claimed by many authors that piezoelectric bone surgery has many advantages, as it decreases heat generation, bone resorption, operative time, risk of soft tissue injuries, and the psychological trauma that results from malleting (17-19).

Horizontal expansion procedures in the present study were performed using 3 non-serrated blunt tips with ascending diameters: CS4 tip of $1.8 \mathrm{~mm}$ in diameter, then CS5 tip of $2.75 \mathrm{~mm}$ in diameter then finally CS6 tip of 3.75 $\mathrm{mm}$ in diameter which are all inserted to the planned full depth of osteotomy (from 6-8mm). These tips allow blunt lateralization of the facial cortex, thus decreasing the risk of fractures and the warming action to the bone that may result from the use of drills; furthermore, they increase the quality of the bone surrounding the implant due to compression of the spongiosa at the side walls of the osteotomy site without any bone removal due to piezoelectric micrometric action. On the other hand, chisels and expanders have the disadvantage of disturbing the patient due to the malleting procedure.

Also with the prescribed technique the indication for crest-splitting can be narrowed down to alveolar crest widths of $1 \mathrm{~mm}$ unlike manual osteotomes or rotating motor driven instruments as saws and burs which were limited to crest-width of minimum $3-4 \mathrm{~mm}$ due to the procedural bone loss up to $3 \mathrm{~mm}$ during the healing period and the need to prepare a mucoperiosteal flap $(20,21)$.

Among the limitations of the ridge splitting technique is the creation of a gap in between the split buccal and lingual bone plates; in the case of immediate implant placement, this gap situated mesial and distal to the implant allows for soft tissue ingrowth. (18) This inter-cortical gap could be filled with autologous bone or allogeneic graft material. In this study, the space between the buccal and lingual cortical plates was filled with self-hardening alloplastic bone material Easy-Graft ${ }^{\mathrm{TM}}$ in order to act as a gap filling material and for its osteoconductive properties.

The use of a resorbable membrane to cover the intercortical graft material has been controversial. It has been advocated by many clinicians $(9,10)$, in order to decrease the crestal bone resorption and to prevent any soft tissue ingress into the split crest. In this study, resorbable membranes were not used as we used a kind of stable selfhardening bone graft material which doesn't need to be covered by a membrane due to action of previously described biolinker. Also the use of membranes would also have interfered with the aim of the study, which was detecting the effect of the periosteum as a biological natural membrane in decreasing the amount of MBL without any added factor. Having placed such membranes on top of the periosteum in the study group and under the mucoperiosteal flap in the control group would have created a new variable affecting the results that would have led to a biased conclusion regarding the effect of the periosteum.

The marginal bone surrounding the implants consists of the crestal portion of the buccal, lingual, mesial, and distal bone plates. To calculate the marginal bone resorption in this study, it was not possible to add the amount of resorption at all the surfaces to each other, due to the fact that the buccal and lingual plates are formed from the native bone, while the mesial and distal plates are formed from the alloplastic bone material and these have different resorption and remodeling patterns. Finally, the amount of marginal resorption for each implant consists of the mean bone loss of the mesiodistal plates together and the bone loss of the buccal and lingual plates together.

In this study, calculations of bone loss were done by measuring the bone height immediately postoperative as baseline, after 3, 6 and 9 months postoperatively for each surface in each group (control and study), from the bottom to the top of the implant (which was used as a reference), in order to measure the amount (in millimetres) and percentage of resorption for each surface and to compare them with those of the other group. The results regarding buccal and lingual bone resorption in this study are close to those obtained by Jensen et al. (22) who measured the amount of labial bone resorption in the ridge splitting technique with simultaneous implant placement. They used clinical measurements that were taken via periodontal probe at 6 months after the implant placement and concluded that the amount of crestal bone loss at the labial plate of bone ranges from 1.5 to $3.5 \mathrm{~mm}$. The higher percentage of resorption that occurred at the crestal portion of the buccal plate was attributed to the following: 1- The blood supply and the revascularization of the crestal portion of the expanded buccal plate was affected by stripping the periosteal attachment in the control group. 2- The movement of the buccal cortex in a lateral direction will also affect its nourishment and blood supply. 3- Almost all the cutting and splitting procedures were done in the crest of the buccal cortex, which may cause its resorption; being relatively thin, the lateralized buccal cortex is more liable to resorption. The present results also showed the mesiodistal bone resorption in the control group to be higher than that of the study group.

\section{CONCLUSIONS}

The analysis of the clinical and radiographic study proved that the piezoelectric ridge splitting technique for immediate management of narrow alveolar crests using a split thickness mucosal flap is a successful option for the reduction of marginal bone level around implants inserted simultaneously after splitting procedure in narrow edentulous posterior mandibular region.

\section{CONFLICT OF INTEREST}

The authors declare that they have no conflicts of interest.

\section{REFERENCES}

1. Wang HL, Boyapati L. Principles of predict-able bone regeneration. Implant Dent 2006; 15:8-17:3.

2. Cordaro L, Amade DS, Cordaro M. Clinical results of alveolar ridge augmentation with mandibular block bone grafts in partially edentulous patients prior to implant place-ment. Clin Oral Implants Res 2002;13: 103-14.

3. Demarosi F, Leghissa GC, Sardella A, Lodi G, Carrassi A. Localised maxillary ridge expansion with simultaneous implant placement: a case series. Br J Oral Maxillofac Surg 2009; 47:535-40.

4. Chin M, Toth BA. Distraction osteogenesis in maxillofacial surgery using internal devices: review of five cases. J Oral Max-illofac Surg 1996; 54:45-53. 
5. Vercellotti T, De Paoli S, Nevins M. The piezoelectric bony window osteotomy and sinus membrane elevation: introduction of a new technique for simplification of the sinus augmentation procedure. Int $\mathrm{J}$ Periodontics Restorative Dent 2001; 21:561-7.

6. Berengo M, Bacci C, Sartori M, Perini A, Della Barbera M, Valente M. Histomorphometric evaluation of bone grafts harvested by different methods. Minerva Stomatol 2006; 55:189-98.

7. Chiapasco M, Romeo E, Vogel G. Tridimen- sional reconstruction of knife edge edentulous maxillae by sinus elevation, onlay grafts and sagittal osteotomy of the anterior maxilla: preliminary surgical and prosthetic results. Int J Oral Maxillofac Implants 1998; 13:394-9. 11.

8. Simion M, Baldoni M, Zaffe D. Jaw bone enlargement using immediate implant place-ment associated with a split-crest technique and guided tissue regeneration. Int $\mathbf{J}$ Periodontics Restorative Dent 1992; 12:462-73.

9. Duncan JM, Westwood RM. Ridge widening for the thin maxilla: a clinical report. Int J Oral Maxillofac Implants 1997; 12:224-7.

10. Shimoyama T, Kaneko T, Shimizu S, Kasai D, Tojo T, Horie N. Ridge widening and immediate implant placement: a case report. Implant Dent 2001; 10:108-12.

11. Scipioni A, Bruschi GB, Calesini G. The edentulous ridge expansion technique: A five-year study. Int J Periodontics Restorative Dent 1994; 14:451-9.

12. Scipioni A, Bruschi GB, Calesini G, Bruschi E, De Martino C. Bone regeneration in the edentulous ridge expansion technique: Histologic and ultrastructural study of 20 clinical cases. Int J Periodontics Restorative Dent 1999; 19:269-77.

13. Chiapasco M, Romeo E, Vogel G. Vertical distraction osteogenesis of edentulous ridges for improvement of oral implant positioning: A clinical report of preliminary results. Int J Oral Maxillofac Implants 2001; 16:43-51

14. Lustmann J, Lewinstein I. Interpositional bone grafting technique to widen narrow maxillary ridge. Int J Oral Maxillofac Implants 1995; 10:568-77.

15. Piccinini M. Mandibular bone expansion technique in conjunction with root form implants: a case report. J Oral MaxillofacSurg 2009; 67:1931-6

16. Sohn DS, Lee HJ, Heo JU, Moon JW, Park IS, Romanos GE. Immediate and delayed lateral ridge expansion technique in the atrophic posterior mandibular ridge. $\mathrm{J}$ Oral Maxillofac Surg 2010; 68:2283-90.

17. Deepak Agrawal, Alka Sanjay Gupta, Vilas Newaskar, Amit Gupta, Subhash Garg Deshraj Jain. Narrow Ridge Management with Ridge Splitting with Piezotome for Implant Placement: Report of 2 Cases. J Indian Prosthodont So 2012. DOI 10.1007/s13191-012-0216-8.

18. Blus C, Szmukler-Moncler S. Split-crest and immediate implant placement with ultrason-ic bone surgery: a 3-year life-table analysis with 230 treated sites. Clin Oral Implants Res 2006; 17:700-7.
19. Troedhan A, Kurrek A, Wainwright M. Vertical alveolar crest split and widening - an experimental study on cow ribs, ultrasonic tool development and test on human cadaver heads. Surg Tech Dev NA 2012, e10. doi:10.4081/std.2012.e10

20. Suh JJ, Shelemay A, Choi SH, Chai JK. Alveolar ridge splitting: A new microsaw technique. Int J Periodontics Restorative Dent 2005;25: 65-171.

21. Rossi Jr R. Performing ridge splitting to allow more bone for implant placement. Dent Implantol Update 1999; 10:12-3.

22. Jensen OT, Cullum DR, Baer D. Marginal bone stability using 3 different flap approaches for alveolar split expansion for den $\neg$ tal implants: a 1-year clinical study. J Oral Maxillofac Surg 2009; 67:1921-30. 